Maffulli N, Caine DJ (eds): Epidemiology of Pediatric Sports Injuries: Team Sports.

Med Sport Sci. Basel, Karger, 2005, vol 49, pp 9-30

\title{
Baseball Injuries
}

\author{
Stephen Lyman, Glenn S. Fleisig \\ American Sports Medicine Institute, Birmingham, Ala., USA
}

\begin{abstract}
Objective: To identify the frequency of injury in youth baseball, risk factors for these injuries, and possible prevention measures to reduce the frequency or severity of these injuries. Data Sources: Information was collected from all known epidemiologic and intervention studies published in the peer-reviewed medical and scientific literature as it applies to youth baseball injuries. Main Results: The frequency and severity of youth baseball injuries have remained relatively consistent over time. Risk factors for many injuries have been understudied and the study designs used for much of this research have been less than optimal. Several effective prevention measures have been identified, such as batting helmets, face shields, softer baseballs, and breakaway bases. Conclusions: Baseball is a relatively safe sport compared to many contact sports, but injuries do still occur. Future research should focus on determining the optimum pitching motion for both arm safety and performance, as well as systematically studying other potential safety improvements such as restrictions against breaking pitches.
\end{abstract}

Copyright (C) 2005 S. Karger AG, Basel

\section{Introduction}

In the United States, over 20 million people play organized baseball per year, a vast majority of whom are children and teenagers [1]. Although baseball is believed to be one of the safest team sports in which athletes participate $[2,3]$, the sheer number of players makes any relatively frequent injuries important to prevent.

The purpose of this chapter is to review the history of published peerreviewed literature on juvenile baseball injuries. The literature review consists of all published English language articles evaluating the epidemiology of baseball injuries in children since 1966 as identified through Medline (descriptors: baseball OR pitching AND child OR adolescent OR youth). The ancestry 
approach was used to identify additional relevant articles not arising from the database search. Only those articles that focused on the frequency and determinants of baseball injury were included in this review.

Many previously published studies of baseball injuries in children suffer from the methodological problems described by Walter and Hart [4]. These studies used varying definitions of injury, making cross-study comparison difficult. In many studies, injury rates were not calculated based on exposure, but rather on participation, even though exposure may differ for each participant. Nearly all reports of youth baseball injury were retrospective, case, or case series. Few studies have used cross-sectional or prospective designs. Only population-based retrospective or prospective cohort studies will be evaluated in this chapter. The volume of case studies and case series is enormous, but of little use in the understanding of the frequency and determinants of baseball injury in children.

\section{Incidence of Injury}

\section{Injury Rates}

A comparison of injury rates in youth $[3,5,6,10,12,16,17]$ and high school $[7-9,11,13-15]$ are shown in table 1 . Overall, the rates of injury in youth and high school baseball are lower than other sports played by children and adolescents, but they still represent a significant cause of injury and potential long-term disability among the participants [18], particularly among pitchers [19-28].

Youth Baseball

For this review, youth baseball was defined as pre-high school recreational league play such as 'Little League'. The original study of the epidemiology of baseball injuries in children by Hale [10] in 1960 retrospectively reviewed insurance claims over a 5 -year period; finding 2.0 injuries per 100 participants. This is likely an underestimate since only athletes making an insurance claim were included as injuries. Many more athletes were likely injured without seeking medical care through the insurance system.

More than 40 years later, Marshall, et al. [12] replicated and expanded upon Dr. Hale's original research by looking at the compensated insurance claims in Little League Baseball. This study demonstrated a very low rate of compensated insurance claims with only 0.62 injuries per 1,000 player-seasons, a substantial reduction from Dr. Hale's original estimates. Either youth baseball has become much safer or league insurance claims are much less common due to private insurance coverage for players. 
Table 1. Comparison of injury rates in baseball

\begin{tabular}{|c|c|c|c|c|c|c|}
\hline Study (year) & $\begin{array}{l}\text { Duration } \\
\text { in years }\end{array}$ & Design & Data source & Participants & Injuries & $\begin{array}{l}\text { Rate per } 100 \\
\text { athletes (unless } \\
\text { otherwise noted) }\end{array}$ \\
\hline
\end{tabular}

\section{Youth}

Hale (1960) [10]

Chambers (1979) [5]

Zaricznyj et al. (1980) [17]

Pasternack et al. (1996) [3]

Cheng et al. (2000) [6]

Radelet et al. (2002) [16]

Marshall et al. (2003) [12]

$\begin{array}{llrrl}\text { Retrospective } & \text { Insurance records } & 771,810 & 15,444 & 2.0 \\ \text { Prospective } & \text { Survey } & 740 & 2 & 0.27 \\ \text { Retrospective } & \text { Survey } & 137 & 13 & 9.5 \\ \text { Prospective } & \text { Survey } & 2,861 & 81 & 2.8 \\ \text { Prospective } & \text { ER records } & 64,075^{\mathrm{a}} & 76 & 0.74^{\mathrm{b}} \\ \text { Prospective } & \text { Survey } & 534 & 117 & 0.17^{\mathrm{c}} \\ \text { Retrospective } & \text { Insurance records } & 6,744,240^{\mathrm{d}} & 4,233 & 0.62^{\mathrm{e}}\end{array}$

High School

Garrick and Requa (1978) [8]

Grana (1979) [9]

Lowe et al. (1987) [11]

Martin et al. (1987) [13]

McLain and Reynolds (1989) [14]

DuRant et al. (1992) [7]

Powell and Barber-Foss (2000) [15] 3

$\begin{array}{llrrr}\text { Prospective } & \text { Survey } & 249 & 46 & 0.18^{c} \\ \text { Retrospective } & \text { Survey } & 1,969 & 29 & 1.47 \\ \text { Retrospective } & \text { Survey } & 256 & 3 & 1.22 \\ \text { Prospective } & \text { Survey } & 148 & 8 & 5.4 \\ \text { Prospective } & \text { Survey } & 68 & 10 & 15.0 \\ \text { Prospective } & \text { Survey } & 108 & 21 & 19.4 \\ \text { Prospective } & \text { Surveillance system } & 2,167 & 861 & 13.2\end{array}$

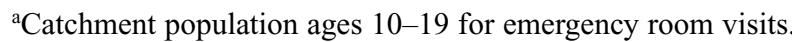

ber 1,000 adolescents ages 10-19.

cper 1,000 athlete-exposures (A-E).

${ }^{\mathrm{d}}$ Count of number of seasons during the three year follow-up period.

eper 1,000 athlete-seasons.

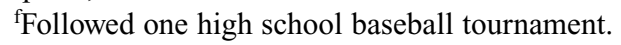


Several smaller studies demonstrated widely disparate injury rates in youth baseball from 0.27 per 100 athletes to 9.5 per 100 athletes [3, 5, 6, 16, 17]. In 2000, Cheng et al. [6] reported 76 baseball-related emergency room visits among adolescents over 2 years in Washington, DC. This translated to an injury rate of 0.74 per 1,000 adolescents, but not all DC area youths played baseball, so this rate is not directly comparable to other rates presented here.

Radelet et al. [16] found an injury rate of 0.17 per 1,000 athletic exposures (A-E). Since this study used A-E rather than a person-based rate denominator, the results are not directly comparable to other studies among children in these ages. Nonetheless, it is likely the most representative study of the true injury rates in youth baseball.

\section{High School Baseball}

Garrick and Requa [8] published the first study of high school baseball injuries in 1978. This was the earliest baseball epidemiology study that used A-E as a rate denominator rather than a count of athletes. The rate of 0.18 per 1,000 A-E translates to a rate of 9.2 injuries per 100 athletes per year (table 1). This is very similar to the rate found by Radalet et al. [16] for youth baseball using very similar methodology. Subsequently, two retrospective studies found injury rates of $1.2-1.5$ per 100 athletes $[9,11]$ and several prospective studies found injury rates from 5.4 (in a single tournament) to 19.4 per 100 athletes [7, 13-15]. A study by Powell and Barber-Foss [15] followed 2,167 high school players prospectively for 3 seasons, making it the largest study of the incidence of high school baseball injury to date. The finding of an injury rate of 13.2 per 100 athletes is in line with previous prospective studies, but may represent the most stable estimate available for the true incidence of baseball injuries in high school athletes due to the large sample size.

The retrospective follow-up studies of high school players have found injury rates of less than 2 per 100 athletes while the prospective follow-up studies of these players have found injury rates of 9 or greater per 100 athletes. This gross disparity suggests that a uniform definition of injury must be identified and that retrospective studies are likely substantially limited by recall bias and under-ascertainment.

\section{Pitching Injuries}

Approximately $25 \%$ of youth baseball players participate as pitchers. Pitching is the primary defensive tool in the sport of baseball, and it requires the repetition of a dynamic arm motion during which the pitcher delivers the ball to the batter. Several studies have found high rates of mild to moderate elbow and shoulder pain in youth and adolescent pitchers. These injuries are believed to be a result of overuse of the affected joints. Furthermore, continued 
overuse is believed to eventually result in serious injury or arm-related disability in some pitchers [18].

Table 2 summarizes the findings of studies of elbow and shoulder injury in pitchers published between 1965 and 2002 [19-28]. In 1965, Adams conducted the seminal epidemiologic study on this issue [19]. This study identified injuries as pitcher self-report of elbow soreness while pitching. Adams compared 3 groups of male children: pitchers, baseball players who did not pitch, and healthy boys who did not play baseball. The frequency of arm pain was highest in pitchers. Subsequent studies of American youth and high school players have demonstrated a prevalence of elbow pain between 18 and $29 \%$ [22, 24, 27, 28] and an incidence of elbow pain of $26 \%$ among youth players and 58\% among high school players [20, 21, 23, 25, 26]. Shoulder pain has not been studied as frequently with a prevalence of $29 \%$ in single study of 9-18-year-old boys [28] and an incidence of $32-35 \%$ in two recent studies by Lyman et al. $[25,26]$.

A Taiwan Little League study evaluated all pitchers participating in the 1980 Taiwan Little League championship tournament [23]. Injury was defined as a complaint of elbow soreness during the tournament. This study evaluated a specific location of elbow injury and found that $41 \%$ of the pitchers experienced tenderness over the medial epicondylar region of the elbow during the tournament. Another Asian study among Japanese High School pitchers was conducted during the Japanese High School Baseball Association national championship [27]. Injury was defined as a self-reported history of shoulder or elbow pain, and a frequency of $38 \%$ was found for each.

All of the above studies used radiographic comparison of pitchers' throwing elbows to their non-throwing elbows. The initial study in 1965 identified radiographic changes in the arms of $95 \%$ of the pitchers compared with $11 \%$ in the group of non-pitching baseball players [19]. Subsequent studies have found radiographic changes in $4-95 \%$ of the elbows of youth and high school pitchers $[6,20-22,24,27,28]$. In no study was the radiographic identification of elbow abnormality correlated with elbow pain. Individual interpretation of the radiographs may explain part of the differences identified. The studies also used inconsistent definitions of abnormal when reviewing radiographs. No study examined the shoulders of these pitchers with radiographs.

Two recent studies found incidence rates of self-reported elbow pain in more than $25 \%$ of pitchers and self-reported shoulder pain in more than $30 \%$ of pitchers $[25,26]$. These studies used a prospective design with pitcher interviews occurring after each game pitched, improving on previous designs in which pitchers were interviewed only after the tournament or season was completed. This reduces recall bias in this young population. Radiographic exams were not 
Table 2. Studies of elbow and shoulder injury in pitchers

\begin{tabular}{|c|c|c|c|c|c|c|c|c|}
\hline Study (year) & Level, Location & Design & $N$ & $\begin{array}{l}\text { Age in } \\
\text { years }\end{array}$ & $\begin{array}{l}\text { Affected } \\
\text { joint }\end{array}$ & $\begin{array}{l}\text { Frequency } \\
\text { measure }\end{array}$ & $\begin{array}{l}\text { Per cent } \\
\text { reporting } \\
\text { pain }\end{array}$ & $\begin{array}{l}\text { Per cent } \\
\text { with X-ray } \\
\text { changes }^{\text {a }}\end{array}$ \\
\hline \multicolumn{9}{|l|}{ Youth Leagues } \\
\hline Adams, (1965) [19] & Various, Calif., USA & Retrospective & 80 & $9-14$ & Elbow & Prevalence & 45 & 95 \\
\hline $\begin{array}{l}\text { Gugenheim et al. } \\
\text { (1976) [22] }\end{array}$ & $\begin{array}{l}\text { Little League, } \\
\text { Tex., USA }\end{array}$ & Retrospective & 595 & $11-12$ & Elbow & Prevalence & 18 & 28 \\
\hline $\begin{array}{l}\text { Larson et al. } \\
\text { (1976) [24] }\end{array}$ & $\begin{array}{l}\text { Little League, } \\
\text { Oreg., USA }\end{array}$ & Retrospective & 120 & $11-12$ & Elbow & Prevalence & 18 & 95 \\
\hline $\begin{array}{l}\text { Albright et al. } \\
\text { (1978) [20] }\end{array}$ & $\begin{array}{l}\text { Little League, } \\
\text { Conn., USA }\end{array}$ & Prospective & 54 & $11-12$ & Both & Incidence & 44 & n.a. \\
\hline Hang (1979) [23] & Little League, Taiwan & Prospective & 112 & $11-12$ & Elbow & Incidence & 69 & 62 \\
\hline $\begin{array}{l}\text { Lyman et al. } \\
(2001)[25]\end{array}$ & Various, Ala., USA & Prospective & 298 & $9-12$ & $\begin{array}{l}\text { Elbow } \\
\text { Shoulder }\end{array}$ & Incidence & $\begin{array}{l}26 \\
32\end{array}$ & n.a. \\
\hline $\begin{array}{l}\text { Lyman et al. } \\
(2002) \text { [26] }\end{array}$ & Various, Ala., USA & Prospective & 488 & $9-14$ & $\begin{array}{l}\text { Elbow } \\
\text { Shoulder }\end{array}$ & Incidence & $\begin{array}{l}28 \\
35\end{array}$ & n.a. \\
\hline $\begin{array}{l}\text { Mixed } \\
\text { Torg et al. } \\
\text { (1972) [28] }\end{array}$ & Boys' Club, Pa., USA & Retrospective & 49 & $9-18$ & $\begin{array}{l}\text { Elbow } \\
\text { Shoulder }\end{array}$ & Prevalence & $\begin{array}{l}29 \\
29\end{array}$ & $\begin{array}{l}4 \\
\text { n.a. }\end{array}$ \\
\hline $\begin{array}{l}\text { High School } \\
\text { Grana and Rashkin } \\
\text { (1980) [21] }\end{array}$ & High School, USA & Prospective & 73 & $15-18$ & Elbow & Incidence & 58 & 56 \\
\hline $\begin{array}{l}\text { Ochi et al. } \\
\text { (1994) [27] }\end{array}$ & High School, Japan & Retrospective & 130 & $15-18$ & $\begin{array}{l}\text { Elbow } \\
\text { Shoulder }\end{array}$ & Prevalence & $\begin{array}{l}38 \\
38\end{array}$ & $\begin{array}{l}43 \\
\text { n.a. }\end{array}$ \\
\hline
\end{tabular}


conducted in this study because previous research had shown no consistent relationship between radiographic abnormalities and arm pain.

\section{Injury Characteristics}

\section{Injury Onset}

Injuries to fielders and batters tend to be acute traumatic injuries due to contact with the ball, bat, another player, the ground, or a base [29]. On the other hand, injuries to pitchers tend to be the result of cumulative microtrauma through the repetitive throwing motion $[30,31]$.

\section{Injury Location}

Head, Face, and Torso

Injuries to the head, face, and torso are relatively uncommon in baseball compared to contact sports such as football, ice hockey, or lacrosse, but they represent an often severe result of baseball participation with fractures, concussion, traumatic brain injury, and sudden death all possible. Marshall et al. [12] reported a risk of facial injury in youth players at 4.1 per 100,000 player-seasons based on insurance claims data with Little League Baseball. A discussion of traumatic brain injury and commotio cordis appears in the Catastrophic Injury section of this chapter.

\section{Upper Extremity}

Injuries to the upper extremity are very common in baseball pitchers and other players as well. The incidence of elbow and shoulder injury in youth baseball has been estimated at $26-35$ per 100 pitchers per season $[25,26]$. The definition of injury in these studies has usually been 'pain' in the elbow or shoulder during or after pitching. While this does not necessarily reflect a medical problem, it does cause discomfort to children participating in a voluntary activity. Perhaps, more importantly, joint pain may be an early indicator of a developing serious overuse injury.

Clinically meaningful elbow and shoulder problems in pitchers have been euphemistically described as 'Little League Elbow' and 'Little League Shoulder' $[23,32]$. This is an unfortunate implication of Little League Baseball, Inc., which has done more research in an effort to prevent arm injuries in youth pitchers than any other youth baseball organization, funding many of the studies presented in this chapter. For the purposes of this discussion, Little League Elbow will be referred to as medial epicondylitis and Little League Shoulder will be referred to as a widening of the proximal humeral epiphysis, both of which are the more medically correct terms. 


\section{Lower Extremity}

Lower extremity injuries are relatively uncommon among youth baseball players [31], but become more common as age increases and the level of play becomes more aggressive [15]. Ankle and knee injuries are frequent as a result of sliding at higher age levels [33].

\section{Action or Activity}

Pitching Injuries

Pitching is likely the most injury-prone activity at all levels of baseball due to the cumulative microtrauma to the elbow and shoulder, but it is possibly most risky among youth players because of their immature skeletons. The severe pitching injuries seen in high school, college, and professional pitchers are likely due to cumulative trauma that began as children.

\section{Batting Injuries}

Danis et al. [34] conducted a study examining the rate of batting injuries, but restricted this to only facial injuries. This study compared youth players using a face shield while batting versus players not wearing a face shield while batting. The results of this comparison will be discussed further in 'practical applications'. However, for the purposes of reporting a background incidence, 5.3 per 100 athletes reported a facial injury while batting during a single youth season. The nature and severity of the injuries was not disclosed.

\section{Base-Running Injuries}

Most injuries which occur during base-running are the result of sliding into bases. Previous research into sliding injuries has focused on comparisons of breakaway bases versus traditional bases and has included youth and adult players as well as baseball and softball leagues. Therefore, the rates of sliding injury found in these studies are not directly applicable to youth baseball, because baseball and softball as well as adults and children have different rates of injuries. These studies will be discussed in 'practical applications'.

Fielding Injuries

No previous studies of fielding injuries are available for review. Fielding injuries are thought to usually occur due to contact with the ball, the ground, another fielder, or a fence [29].

\section{Chronometry}

Radalet et al. [16] found a significant difference in the risk of injury between games and practice with injuries in games four times more common 
than injuries during practice. Powell and Barber-Foss [35] found a similar relationship for the risk of traumatic brain injury in high school players between games and practices.

\section{Injury Severity}

Most baseball injuries among children and adolescents are not severe. Abrasions are the most common injury types followed by fractures, sprains/ strains, and lacerations. With the exception of sprains of the ligaments or tendons, all of these injuries should heal completely with little or no residual deficit. However, if left untreated, a ligament or tendon injury may cause continued pain with participation or may contribute to a loss of playing ability.

\section{Injury Type}

Previous studies of the types of injuries in youth baseball have found that abrasions are the most common type of injury $[10,36]$, while fractures, sprains/strains, and lacerations follow. A single report of high school injury types reported fractures, sprains, and lacerations as having nearly equal frequency [11]. The utility of this information is suspect, because studies often used differing definitions of 'injury'. Some studies required only self-report of injury [13, 22, 24-26], some required a hospital visit [6], while some required an insurance claim [10,12]. Since abrasions might not require medical attention from a trained health professional or an insurance claim, these are likely greatly under-reported in some studies. Also, since these injuries are common, but mild, they may not be an important part of the safety of youth baseball.

Medical epicondylitis, or pain and inflammation in the medial aspect of the elbow joint, is a common injury among youth pitchers likely because of the secondary ossification centers present in the young elbow. Between the ages of 2 and 11, no less than 6 of these secondary bone growth centers develop in the elbow joint, fusing to the ends of the long bones between the ages of 13 and 17 [37]. These unattached bony growths make the young elbow particularly vulnerable to injury because the elbow does not have the stability of a skeletally mature athlete's elbow.

Widening of the proximal humeral epiphysis occurs from repetitive pitching in the skeletally immature athlete [37-39]. This widening of the growth plate in the proximal end of the humeral shaft may result in pain during or after pitching and may result in deformity if left untreated [32]. A less common, but more traumatic upper extremity injury is the fracture of the humeral shaft due to rotational forces during throwing [40]. 


\section{Catastrophic Injury}

Commotio cordis is the most common cause of injury death as a result of playing baseball [41-43]. Spinal and severe head injuries are much less common in baseball than in contact sports such as football or ice hockey [35].

Maron et al. [43] reported on 128 cases of commotio cordis, which is cardiac arrest as a result of blunt trauma to the chest, from all causes in the USA over a more than 20-year period. Of these cases, 107 died as a result of their injury with 53 of the cases the result of a blow from a thrown or batted baseball. The median age of these victims was 14 years.

Powell and Barber-Foss [35] conducted a study of traumatic brain injury in high school athletes, finding that baseball had the lowest risk of traumatic brain injury among the major sports (baseball, basketball, football, soccer, and wrestling) with a rate of 0.05 per 1,000 A-E. Nine of the fifteen traumatic brain injuries reported among baseball players occurred during a collision with another player, 3 with a bat, 2 with a pitch, and 1 from sliding. Fewer than half of the athletes missed more than a week of participation and none missed more than 3 weeks.

\section{Time Loss}

Time loss from practice or competition has been evaluated in only two studies, both among high school athletes. Garrick and Requa [8] found that $27 \%$ of baseball players lost at least 5 days of practice or games to injury. Powell and Barber-Foss [35] found that the median time lost due to traumatic brain injury for baseball players was 3 days with no player requiring more than 3 weeks to recover.

\section{Clinical Outcome}

Francis et al. [18] reported that $15 \%$ of a sample of 398 male college students who pitched in youth baseball felt their ability to throw in college was hindered or hampered by pain, tenderness, or limitation of movement as a result of their youth baseball pitching. Also, 58\% reported having experienced arm pain at some point during their youth league years. Radiographic evaluation found no differences between those who reported pain and those who did not. This is not surprising since none of the studies that evaluated radiographic changes have linked these changes to injury. Nevertheless, this study suggests a potential for sports-related disability that is associated with youth baseball pitching and continues into adulthood. No similar study of the long-term effects of baseball participation has been conducted for other baseball injuries. 


\section{Injury Risk Factors}

Compared to research in other medical research areas, the risk factor literature on youth baseball injuries is relatively sparse. However, some clear patterns have emerged. Table 3 presents the intrinsic and extrinsic risk factors identified, or at least explored, in the youth baseball injury literature $[3,5,7$, $10,12-16,20,21,25,26,29,36,42-47]$. Levels of evidence were subjectively graded on a four-point scale - high (multiple studies confirming a strong association), moderate (at least one study confirming a modest association), fair (at least one study confirming a modest association, but with at least one other study with a null finding), and low (small association found in only one study, but contradicted in other studies).

\section{Intrinsic Factors}

Intrinsic risk factors are usually not modifiable (e.g. age, race, sex), which makes them of limited utility when attempting to intervene to prevent injury. However, those that are significantly associated with the risk of injury should be accounted for in analyses of modifiable risk factors. Fortunately, in baseball there are several modifiable intrinsic risk factors, particularly with regard to the motions players use to complete tasks such as batting, throwing, sliding, fielding, and pitching.

\section{Non-Pitchers}

Many intrinsic injury risk factors for non-pitchers are similar to those in pitchers, but have not been explored as thoroughly. High school injury rates are consistently higher than youth baseball injury rates. This suggests that level of play increases the risk of injury as bigger, stronger, and more aggressive players play the game with faster throws, harder hits, and faster running. High school players have a greater risk of injuring their lower extremities than younger players, which may be attributed to a more aggressive style of play $[15,31]$ (table 3 ). However, younger players are more likely to suffer injuries from pitched or batted balls $[10,29,36]$.

\section{Pitchers}

Age, Height, and Weight. Lyman et al. [25] found that among 9-12-year-old pitchers, the risk of elbow pain increased with age and body weight [25]. The association with age is likely due to the development of additional secondary ossification centers about the elbow between the ages of 9 and 12 years. Conversely, height was associated with a decreased risk of elbow pain, which may be an indication of skeletal maturity with those secondary ossification centers having fused. With regard to the shoulder, age was associated with a 
Table 3. Risk factors for baseball injuries in youth players

\begin{tabular}{lll}
\hline Risk factor & $\begin{array}{l}\text { Description } \\
\text { of association }\end{array}$ & $\begin{array}{l}\text { Level of } \\
\text { evidence }\end{array}$ \\
\hline
\end{tabular}

Intrinsic risk factors:

Field players:

Older players

$[3,5,7,13-16]$

High school players have higher injury

Fair rates than youth players across prospective studies, but this has not been demonstrated within a single population.

Younger players

$[10,29,36]$

Younger players have consistently been demonstrated to be at increased risk of injury from pitched or batted balls.

Pitchers:

Age [25, 26]

Increasing age was associated with an increased risk of elbow pain in a single prospective study of youth pitchers. A subsequent evaluation of youth pitchers did not demonstrate a clear relationship.

Body weight [25]

Increasing weight was associated with increased risk of elbow pain in a single prospective study of youth pitchers.

Height [25]

Increasing height was associated with a decreased risk of elbow pain and an increased risk of shoulder pain in a single prospective study of youth pitchers.

Pitching motion $[20,21,26]$

Sidearm pitching motion was

Fair associated with an increased risk of elbow pain in a single small prospective study of youth pitchers. No other studies have demonstrated a relationship.

Self-satisfaction with performance [25]

Pitchers less satisfied with their pitching performance were more likely to report elbow and shoulder pain in a single prospective study of youth pitchers.

Moderate

Moderate

Moderate

Moderate

Extrinsic risk factors:

Field players:

Baseball hardness

[12, 42, 43-45]

Both animal and clinical studies have demonstrated that harder baseballs result in more injuries and a higher risk of commotio cordis.

Fixed bases [46, 47]

Intervention trials have demonstrated

High that fixed bases result in far more lower extremity injuries than breakaway bases.

High 
Table 3 (continued)

\begin{tabular}{|c|c|c|}
\hline Risk factor & $\begin{array}{l}\text { Description } \\
\text { of association }\end{array}$ & $\begin{array}{l}\text { Level of } \\
\text { evidence }\end{array}$ \\
\hline \multicolumn{3}{|l|}{ Pitchers (youth only): } \\
\hline $\begin{array}{l}\text { Pitches thrown per } \\
\text { game }[25,26]\end{array}$ & $\begin{array}{l}\text { Two prospective cohort studies have } \\
\text { demonstrated an increased risk of } \\
\text { shoulder pain with increasing game } \\
\text { pitch counts. }\end{array}$ & High \\
\hline $\begin{array}{l}\text { Pitches thrown per } \\
\text { season }[25,26]\end{array}$ & $\begin{array}{l}\text { Two prospective cohort studies have } \\
\text { demonstrated an increased risk of elbow } \\
\text { and shoulder pain with increasing } \\
\text { season pitch counts. }\end{array}$ & High \\
\hline $\begin{array}{l}\text { Curveball use } \\
{[25,26]}\end{array}$ & $\begin{array}{l}\text { A single prospective cohort study } \\
\text { demonstrated a } 50 \% \text { increased risk } \\
\text { of shoulder pain with curveball use, } \\
\text { but another study showed no } \\
\text { association. }\end{array}$ & Fair \\
\hline Slider use $[25,26]$ & $\begin{array}{l}\text { A single prospective cohort study } \\
\text { demonstrated an } 80 \% \text { increased } \\
\text { risk of elbow pain with slider } \\
\text { use, but another study showed } \\
\text { no association. }\end{array}$ & Fair \\
\hline $\begin{array}{l}\text { Change-up use } \\
{[25,26]}\end{array}$ & $\begin{array}{l}\text { Two prospective studies have demonstrated } \\
\text { a consistent, but nonsignificant } 30 \% \\
\text { decreased risk of shoulder pain with } \\
\text { change-up use. }\end{array}$ & Moderate \\
\hline Weightlifting [25] & $\begin{array}{l}\text { A single prospective cohort study found } \\
\text { an association between weightlifting } \\
\text { and elbow pain in youth pitchers. }\end{array}$ & Moderate \\
\hline $\begin{array}{l}\text { Playing baseball outside } \\
\text { of organized league } \\
\text { play [25] }\end{array}$ & $\begin{array}{l}\text { A single prospective cohort study } \\
\text { found an association between playing } \\
\text { outside of organized league play and } \\
\text { increased risk of elbow pain. }\end{array}$ & Moderate \\
\hline
\end{tabular}

nonsignificant decreased risk of shoulder pain, while height was associated with a nonsignificant increased risk of shoulder pain.

Pitching Motion. Albright et al. [20] found that youth pitchers who threw with a sidearm motion rather than overhand motion were at increased risk of elbow pain. Other aspects of the pitching motion were evaluated, but none were found to be significant.

Grana and Rashkin [21] attempted to qualify the pitching motion in high school pitchers using three separate indices: orientation of the hand to the 
shoulder, velocity, and pitching style. None of these indices were associated with current elbow pain except among those pitchers with previous injury, who were more likely to have a loose orientation and moderate velocity. The investigators concluded that this association was likely a result of compensation for the previous injury rather than a cause of the current injury. While this study predates modern biomechanical analysis of the pitching motion, it provided the first look at the motion as a risk factor for arm injury in young players.

Lyman et al. [26] attempted to use a qualitative measure of the pitching motion developed by the American Sports Medicine Institute (ASMI) to correlate the pitching motion with elbow or shoulder problems. The only correlation found that mechanical 'flaws' decreased the risk of elbow and shoulder pain. This correlation may be due to limitations in the study, including qualitative analysis of pitching mechanics from video, the skill level of the subjects, limitations to the normative ASMI model, and the sample size.

Research conducted at ASMI has quantified shoulder and elbow kinetics (i.e. forces and torques) with implications for injury mechanisms [48, 49]. Proper pitching kinematics (i.e. motions) have also been quantified [50, 51], and a relationship between improper kinematics and increased kinetics has been demonstrated [52]. A recent study found that there are few differences between youth and adult pitching kinematics, implying that a youth pitcher may be able to learn proper mechanics at a young age [53].

Self-Satisfaction. The role of psychology in the self-report of injury should not be overlooked when conducting research in pediatric athletes. Lyman et al. [25] asked pitchers to rate their performance in each game pitched. Their level of self-satisfaction was inversely related to their likelihood of claiming to have experienced arm pain as a result of pitching in that game. Whether this represented using pain as an excuse for performance or reason for performance is unknown. There was no association between perceived performance and actual performance (e.g. runs allowed or being the winning pitcher).

\section{Extrinsic Factors}

Non-Pitchers

The extrinsic risk factors associated with injuries in non-pitchers are primarily related to the environment in which the game is played: the hardness of the baseball, the rigidity of bases, and the protective equipment used while batting, fielding, and base-running.

Baseball Hardness. Impact trauma from the baseball or a baseball bat is a common cause of injury during competition. Efforts have been made to decrease the hardness of baseballs used among younger players in an effort to reduce the frequency of contusions, fractures, and most importantly, commotio cordis $[12,44]$. Despite the laboratory-based efficacy of these softer baseballs 
at reducing the likelihood of impact trauma, 2 cases of commotio cordis have been reported after chest wall contact with a reduced-impact baseball [43]. Also, these reduced impact baseballs may increase the severity of eye injury based on laboratory testing of the deformity characteristics of these balls [45].

Fixed Bases. Sliding injuries due to contact with the fixed base are relatively common and can be quite serious with ankle fractures and sprains and knee sprains being common injuries during sliding or base-running [46, 47]. Efforts to teach proper sliding technique may have limited utility [34, 47], but as has been demonstrated time and again in all areas of disease and injury prevention, it is more effective to change the environment than change human behavior. Breakaway bases provide just such an environmental change and have been proven effective $[46,47]$.

\section{Pitchers}

Extrinsic risk factors for injuries to pitchers apart from those associated with reducing the risk of injury from batted balls have focused primarily on the types of pitches thrown and the number of pitches thrown.

Pitch Counts. Gugenheim et al. [22] calculated the average pitches per inning for approximately $25 \%$ of the pitchers in the study. No association was found between average pitches per inning and self-reported elbow pain. The authors stated that this was probably because those pitchers who threw more pitches per inning were not used as often as those with better control.

The first study conducted by Lyman et al. [25] looked at the number of pitches thrown in a game and during the season among pitchers aged 9-12 [25]. There was no significant association between pitches thrown during a game and elbow pain. However, a highly significant dose-response relationship was found for shoulder pain as game pitches increased. The second study conducted by Lyman et al. [26] replicated the methods of the first study with a larger sample size, with a broader age range (9-14), and from a larger geographic area and found a similar association with regard to game pitches [26].

The total number of pitches thrown in a season told a different story. Pitchers who threw a high number of pitches over the course of the season in the first Lyman study had a significantly increased risk of elbow pain and a significantly decreased risk of shoulder pain [25]. The decreased risk of shoulder pain was thought to be due to survivorship, in which pitchers who had low cumulative pitch counts were those who stopped pitching or reduced their workload to avoid shoulder pain. Replication of this study did not yield the same results with the risk of both elbow and shoulder pain increasing as cumulative season pitches increased [26].

Pitch Types. Grana and Rashkin's [21] study of high school pitchers stated that approximately $80 \%$ of the pitches thrown were breaking pitches 
(i.e. pitches that are thrown with the intention of deceiving the hitter through downward or horizontal movement of the ball during flight). No attempt was made to examine the relationship between these pitches and risk of elbow pain. Lyman et al. [25] considered pitch types in both studies. In the first study, the sinkerball or forkball was found to be associated with a nonsignificant $(p=0.06)$ elevated risk of elbow pain. In a stratified analysis, older pitchers who threw a change-up had a significantly decreased risk of elbow pain. In the second study by Lyman et al. [26] change-up use showed a general decrease in the risk of shoulder pain, but it was not a significant association. However, use of the curveball was associated with a significant increased risk of shoulder pain and use of the slider was associated with a significant increased risk of elbow pain.

Research has been conducted to compare the biomechanics of the fastball and the two most common breaking pitches, the curveball and the slider. The results indicate that the curveball may be the most difficult and dangerous pitch to learn, as it requires large forces and torques at the elbow and shoulder like a fastball and slider, but with significantly different mechanics [54, 55].

Other factors. Two other risk factors for elbow pain identified by Lyman et al. [25] are weightlifting and playing baseball outside of the league. The weightlifting association is of little utility, because it is unknown what type of weightlifting was performed and how frequently. There may be arm-strengthening exercises that are not detrimental to elbow health in pitchers. Playing baseball outside of the league likely elevated the pitch counts beyond those recorded in the study, contributing to further overuse of the elbow. This finding could be extended to pitching in multiple leagues, which may double the pitch counts for pitchers.

\section{Suggestions for Injury Prevention}

Several studies have demonstrated injury prevention tools for youth baseball players through either equipment changes or behavioral modifications. Table 4 presents the injury prevention methods previously studied that may improve youth baseball safety [12, 26, 29, 35, 44-47, 56]. Levels of evidence were subjectively graded on a four-point scale - high (multiple studies confirming a strong protective effect), moderate (at least one study confirming a modest protective effect), fair (at least one study confirming a modest protective effect, but with at least one other study with a null finding), and low (small protective effect found in one study, but contradicted in other studies).

\section{Batting Helmets and Face Guards}

Batting helmets have been in use in youth and high school baseball for decades. Seminal work done by Dr. Creighton Hale of Little League Baseball, Inc. 
Table 4. Interventions for increasing youth baseball safety

\begin{tabular}{|c|c|c|}
\hline Intervention & $\begin{array}{l}\text { Safety } \\
\text { advantage }\end{array}$ & $\begin{array}{l}\text { Level of } \\
\text { evidence }\end{array}$ \\
\hline Batting helmets $[29,56]$ & $\begin{array}{l}\text { Batting helmets offer significant } \\
\text { protection from head injury and are } \\
\text { used at all levels of organized baseball. }\end{array}$ & High \\
\hline Face guards $[12,35]$ & $\begin{array}{l}\text { Face guards lower the risk of facial } \\
\text { and dental injury and have become } \\
\text { increasingly accepted at lower } \\
\text { levels of youth baseball. }\end{array}$ & High \\
\hline Safety baseballs $[12,44,45]$ & $\begin{array}{l}\text { Safety baseballs are softer than } \\
\text { traditional baseballs. They reduce the } \\
\text { risk of contusions and other injuries } \\
\text { associated with baseballs, but the } \\
\text { current designs may increase the } \\
\text { risk of eye injury due to their } \\
\text { deformity characteristics. }\end{array}$ & Moderate \\
\hline Breakaway bases $[46,47]$ & $\begin{array}{l}\text { Several intervention trials have } \\
\text { demonstrated a greatly reduced } \\
\text { risk of lower extremity injury } \\
\text { from sliding. }\end{array}$ & High \\
\hline Sliding techniques [24] & $\begin{array}{l}\text { Reducing sliding injuries through education } \\
\text { has been largely ineffective - breakaway } \\
\text { bases represent a much more effective } \\
\text { intervention. }\end{array}$ & Low \\
\hline Pitching limits $[25,26]$ & $\begin{array}{l}\text { Pitch limits have not been instituted at } \\
\text { any level of youth competition, though } \\
\text { weekly innings limits have been in use } \\
\text { for decades in youth baseball. In theory, } \\
\text { pitch limits would improve safety. }\end{array}$ & Moderate \\
\hline Pitch types $[25,26,57]$ & $\begin{array}{l}\text { There is no evidence that prohibiting } \\
\text { pitch types that young pitchers use } \\
\text { reduces the risk of arm injury. In } \\
\text { theory this may improve safety, but no } \\
\text { studies have been conducted. }\end{array}$ & Fair \\
\hline
\end{tabular}

helped develop these helmets and disseminate this information throughout organized baseball [56]. While head and facial injuries still occur to batters, they are much less frequent than they would be without batting helmets.

Research has demonstrated a reduction in the risk of facial and eye injuries with the use of face guards while batting [12,35]. Marshall et al. [12] found an approximately $35 \%$ reduction in risk of facial injury in youth leagues using face shields compared to youth leagues without. Face shields are currently used 
in virtually all younger youth baseball leagues and many older youth baseball leagues. High school players have not consistently used face shields, likely because the ability to see high velocity pitches and breaking pitches is compromised even with a clear plastic visor. This balance between safety and performance is one made almost daily by athletes in all sports at all levels. Given that younger players are at higher risk of injury from pitched or batted balls $[10,29,36]$, this shift from face shield use to non-use represents a shift in the balance between safety and performance.

\section{Safety Baseballs}

Several companies have developed a variety of low-impact baseballs for use by youth baseball leagues to reduce the likelihood of injury from blunt impact trauma from a thrown or batted ball $[12,44]$. These balls are designed to mimic the play characteristics of a regulation hard ball, but with softer materials. Some laboratory testing suggests that these balls may increase the risk of ocular trauma because the ball deforms deeper into the eye socket, causing more damage to eye tissue [45]. However, the large number of other injuries that may be prevented including fractures and commotio cordis may justify the potential increased risk of serious ocular trauma, particularly if these balls are used in conjunction with face shields. A recent study by Marshall et al. [12] evaluated the risk of injury in leagues using softer baseballs and found an approximately $23 \%$ reduction in risk of ball-related injury.

\section{Breakaway Bases}

While research has been conducted in proper sliding techniques [46, 47], breakaway bases likely provide a much greater risk reduction without a substantial increase in cost (current designs cost approximately what traditional bases do) [47]. The increased safety achieved with these breakaway base designs appears unequivocal and should be used to reduce serious slide-related sprains and fractures seen at all levels of play $[47,58]$.

\section{Proper Techniques}

Many coaches, baseball experts, and researchers claim to know the best or safest way to perform baseball skills such as pitching, hitting, fielding, or baserunning, but there is currently a paucity of scientific evidence that any of these techniques are meaningfully safer or result in improved performance.

\section{Pitching Limits}

Youth baseball leagues regulate the number of innings pitchers pitch per week, but the current standards may be inadequate to prevent arm injuries. Unfortunately, no systematic research on the effect of these changes was undertaken and studies from before and after the intervention are not readily 
comparable due to differences in the measurement of injury and broader societal changes that may influence changes in injury risk.

Youth leagues currently have limits on the number of innings pitched (e.g. 6-12 innings pitched per week) and required rest periods (e.g. minimum of 48 hours rest after at least two innings pitched). These regulations apply to all pitchers within a youth league organization [59]. A difficulty with this regulatory system is that younger pitchers tend to throw more pitches per inning than older pitchers because they have less control over their pitches because of lack of experience, greater musculoskeletal immaturity, or both [60]. Therefore, with innings limits, those with potentially weaker and less developed arms are throwing more pitches than those with stronger arms. It is possible that these youth league organizations could more effectively prevent these injuries in pitchers with pitch limits or batter limits. To educate about the potential safety benefits of pitch count limits, the Medical and Safety Committee of USA Baseball published a position statement on their website (www.usabaseball.com/med_position_statement.html).

\section{Pitch Types}

Curveballs and other breaking pitches have long been implicated anecdotally with arm injuries in children, but until recently, the association has not been scientifically established $[25,26]$. While evidence now suggests that the risk of arm problems is elevated with breaking pitch use, it may not be strong enough to discourage children, parents, and coaches from using breaking pitches, because breaking pitches provide a distinct advantage against young batters.

Perhaps a more compelling argument against the use of breaking pitches among young pitchers is based upon the childhood dream of becoming a major league baseball player. Dr. Joe Chandler of the Atlanta Braves explained that this team was much more interested in pitching velocity, pitch location, and the ability to change speeds (i.e. throw a change-up) than in the ability to throw breaking pitches [57]. In fact, the average age at which pitchers in the Atlanta Braves organization learned to throw a curveball was 14.5 years. Therefore, there may be long-term benefits for a youth pitcher to concentrate on arm strength for velocity, accuracy for pitch location, and getting batters out with a strong fastball and slow change-up rather than relying on curveballs to get batters out more easily.

\section{Suggestions for Future Research}

The primary challenges in sports injury prevention research in general and baseball injury prevention research in particular, is the definition of 'injury' and the definition of 'exposure'. The studies reviewed here used a variety of 
injury definitions from self-reported pain to an injury requiring missed games or practices to emergency room care to insurance claims. A clear and consistent definition of injury is vital to additional and improved understanding of baseball injuries.

Furthermore, exposure has been defined in a variety of ways from counting players to counting games or practices to counting pitches. Given that many of the current sports injury surveillance systems use a measure of athlete-exposures (one athlete exposure is one game or practice session for one athlete), this is probably the best definition of exposure and allows for future studies to be compared with many previous studies in the literature. However, this is really only an acceptable exposure definition of non-pitchers. Starting pitchers and relief pitchers have very different exposure levels during a pitching appearance so number of innings, batters, or pitches may be a better marker of exposure.

Future research efforts should focus primarily on identifying safe pitching mechanics for young pitchers and identifying the optimal balance point between skill development and safety in pitchers - the balance between pitching too much and too little. With the proven effectiveness of safety baseballs, face shields, and breakaway bases, the next wave of equipment innovation should focus on making a face shield that is acceptable to players at higher skill levels, developing a soft baseball that has play characteristics identical to traditional baseballs, and identifying other equipment improvements that can protect young baseball players as they enjoy the game.

These research endeavors would ideally be conducted using randomized controlled intervention trial methodology unless impractical. In those cases, the research should be conducted using a prospective cohort design.

\section{References}

1 USA Baseball. This is USA Baseball. internet. 2004.

2 American Academy of Pediatrics: Risk of injury from baseball and softball in children. Pediatrics 2001;107:782-784.

3 Pasternack JS, Veenema KR, Callahan CM: Baseball injuries: A Little League survey. Pediatrics 1996;98:445-448.

4 Walter S, Hart L: Application of epidemiological methodology to sports and exercise science research; in Pandolf K, Holloszy J (eds): Exercise and Sports Science Reviews, ed1. Baltimore, Williams \& Wilkens, 1990, pp 417-448.

5 Chambers RB: Orthopaedic injuries in athletes (ages 6 to 17). Comparison of injuries occurring in six sports. Am J Sports Med 1979;7:195-197.

6 Cheng TL, Fields CB, Brenner RA, Wright JL, Lomax T, Scheidt PC: Sports injuries: An important cause of morbidity in urban youth. District of Columbia Child/Adolescent Injury Research Network. Pediatrics 2000;105:E32.

7 DuRant RH, Pendergrast RA, Seymore C, Gaillard G, Donner J: Findings from the preparticipation athletic examination and athletic injuries. Am J Dis Child 1992;146:85-91.

8 Garrick JG, Requa RK: Injuries in high school sports. Pediatrics 1978;61:465-469. 
9 Grana WA: Summary of 1978-79 injury registry for Oklahoma secondary schools. J Oklahoma Med Assoc 1979;72:369-372.

10 Hale CJ: Injuries among 771,810 little league baseball players. J Sports Med Phys Fitness $1961 ; 1: 80-83$.

11 Lowe EB, Perkins ER, Herndon JH: Rhode Island high school athletic injuries 1985-1986. RI Med J 1987;70:265-270.

12 Marshall SW, Mueller FO, Kirby DP, Yang J: Evaluation of safety balls and faceguards for prevention of injuries in youth baseball. JAMA 2003;289:568-574.

13 Martin RK, Yesalis CE, Foster D, Albright JP: Sports injuries at the 1985 Junior Olympics. Am J Sports Med 1987;15:603-608.

14 McClain LG, Reynolds S: Sports injuries in high school. Pediatrics 1989;84:446-450.

15 Powell JW, Barber-Foss KD: Sex-related injury patterns among selected high school sports. Am J Sports Med 2000;28:385-391.

16 Radelet MA, Lephart SM, Rubinstein EN, Myers JB: Survey of the injury rate for children in community sports. Pediatrics 2002;110:e28.

17 Zaricznyj B, Shattuck LJM, Mast TA, Roberston RV, Delia G: Sports-related injuries in school age children. Am J Sports Med 1980;8:318-324.

18 Francis R, Bunch T, Chandler B: Little league elbow: A decade later. Phys Sportsmed 1978;6:88-94.

19 Adams JE: Injury to the throwing arm: A study of traumatic changes in the elbow joints of boy baseball players. Calif Med 1965;102:127-132.

20 Albright JA, Jok1 P, Shaw R, Albright JP: Clinical study of baseball pitchers: Correlation of injury to the throwing arm with method of delivery. Am J Sports Med 1978;6:15-21.

21 Grana WA, Rashkin A: Pitcher's elbow in adolescents. Am J Sports Med 1980;8:333-336.

22 Gugenheim JJ Jr, Stanley RF, Woods GW, Tullos HS: Little League survey: The Houston study. Am J Sports Med 1976;4:189-200.

23 Hang YS, Lippert FG III, Spolek GA, Frankel VH, Harrington RM: Biomechanical study of the pitching elbow. Int Orthop 1979;3:217-223.

24 Larson RL, Singer KM, Bergstrom R, Thomas S: Little League survey: The Eugene study. Am J Sports Med 1976;4:201-209.

25 Lyman S, Fleisig GS, Waterbor JW, Funkhouser EM, Pulley L, Andrews JR, Osinski ED, Roseman JM: Longitudinal study of elbow and shoulder pain in youth baseball pitchers. Med Sci Sports Exerc 2001;33:1803-1810.

26 Lyman S, Fleisig GS, Andrews JR, Osinski ED: Effect of pitch type, pitch count, and pitching mechanics on risk of elbow and shoulder pain in youth baseball pitchers. Am J Sports Med 2002;30:463-468.

27 Ochi, T, Shimaoka Y, Nakagawa S: Enactment of a provision for restricting pitching in national high school championship games. Clin Sports Med 1994;11:851-853.

28 Torg JS, Pollack H, Sweterlitsch P: The effect of competitive pitching on the shoulders and elbows of preadolescent baseball players. Pediatrics 1972;49:267-272.

29 Hale CJ: Protective Equipment for Baseball. Phys Sportsmed 1979;7:58-63.

30 Andrews JR, Fleisig GS: Preventing throwing injuries. J Orthop Sports Phys Ther 1998;27:187-188.

31 Yen KL, Metzl JD: Sports-specific concerns in the young athlete: Baseball. Pediatr Emerg Care 2000;16:215-220.

32 Carson WG Jr, Gasser SI: Little Leaguer's shoulder. A report of 23 cases. Am J Sports Med 1998;26:575-580.

33 Janda DH, Wojtys EM, Hankin FM, Benedict ME: Softball sliding injuries. A prospective study comparing standard and modified bases. JAMA 1988;259:1848-1850.

34 Danis RP, Hu K, Bell M: Acceptability of baseball face guards and reduction of oculofacial injury in receptive youth league players. Inj Prev 2000;6:232-234.

35 Powell JW, Barber-Foss KD: Traumatic brain injury in high school athletes. JAMA 1999;282: 958-963.

36 Heald J: Summary of baseball/softball injuries. 1991. Tullahoma, TN, Worth Sports Company. Ref Type: Pamphlet.

37 Hutchinson MR, Ireland ML: Overuse and throwing injuries in the skeletally immature athlete. Instr Course Lect 2003;52:25-36. 
38 Hale CJ: Little Leaguer's shoulder: A report of 23 cases. Am J Sports Med 1999;27:269.

39 Lipscomb AB: Baseball pitching injuries in growing athletes. J Sports Med 1975;3:25-34.

40 Hennigan SP, Bush-Joseph CA, Kuo KN, Bach BR Jr: Throwing-induced humeral shaft fracture in skeletally immature adolescents. Orthopedics 1999;22:621-622.

41 Abrunzo TJ: Commotio cordis. The single, most common cause of traumatic death in youth baseball. Am J Dis Child 1991;145:1279-1282.

42 Maron BJ, Poliac LC, Kaplan JA, Mueller FO: Blunt impact to the chest leading to sudden death from cardiac arrest during sports activities. N Engl J Med 1995;333:337-342.

43 Maron BJ, Gohman TE, Kyle SB, Estes NA III, Link MS: Clinical profile and spectrum of commotio cordis. JAMA 2002;287:1142-1146.

44 Yamamoto LG, Inaba AS, Okamura DM, Yamamoto JA, Yamamoto JB: Injury reduction and bounce characteristics of safety baseballs and acceptability by youth leagues. Clin Pediatr (Phila) 2001;40:197-203.

45 Vinger PF, Duma SM, Crandall J: Baseball hardness as a risk factor for eye injuries. Arch Ophthalmol 1999;117:354-358.

46 Janda DH, Bir C, Kedroske B: A comparison of standard vs. breakaway bases: An analysis of a preventative intervention for softball and baseball foot and ankle injuries. Foot Ankle Int 2001;22: 810-816.

47 Sendre RA, Keating TM, Hornak JE, Newitt PA: Use of the Hollywood Impact Base and standard stationary base to reduce sliding and base-running injuries in baseball and softball. Am J Sports Med 1994;22:450-453.

48 Fleisig GS, Andrews JR, Dillman CJ, Escamilla RF: Kinetics of baseball pitching with implications about injury mechanisms. Am J Sports Med 1995;23:233-239.

49 Fleisig GS, Barrentine SW, Escamilla RF, Andrews JR: Biomechanics of overhand throwing with implications for injuries. Sports Med 1996;21:421-437.

50 Dillman CJ, Fleisig GS, Andrews JR: Biomechanics of pitching with emphasis upon shoulder kinematics. J Orthop Sports Phys Ther 1993;18:402-408.

51 Fleisig GS, Dillman CJ, Andrews JR: Proper mechanics for baseball pitching. Clin Sports Med 1989;1:151-170.

52 Fleisig GS: The biomechanics of baseball pitching; Thesis, University of Alabama at Birmingham, 1994.

53 Fleisig GS, Barrentine SW, Zheng N, Escamilla RF, Andrews JR: Kinematic and kinetic comparison of baseball pitching among various levels of development. J Biomech 1999;32:1371-1375.

54 Elliott B, Grove JR, Gibson B, Thurston B: Three-dimensional cinematographic analysis of the fastball and curveball pitches in baseball. Int J Sport Biomech 1986;2:20-28.

55 Escamilla RF, Fleisig GS, Barrentine SW, Zheng N, Andrews JR: Kinematic comparisons of throwing different types of baseball pitches. J Appl Biomech 1998;14:1-23.

56 Hale CJ, Lyman S, Fleisig GS: 1998. Pers. Commun.

57 Chandler J: The epidemic of baseball injuries in youth baseball - Is prevention possible? Birmingham AL, American Sports Medicine Institute. Proceedings of the 21st Annual Injuries in Baseball Course. 1-23-2003.

58 Janda DH, Hankin FM, Wojtys EM: Softball injuries: Cost, cause and prevention. Am Fam Physician 1986;33:143-144.

59 Andrews JR, Fleisig GS: Medical and Safety Advisory Committee Special Report: How many pitches should I allow my child to throw? USA Baseball News 5, 1996.

60 Axe MJ, Snyder-Mackler L, Konin JG, Strube MJ: Development of a distance-based interval throwing program for Little League-aged athletes. Am J Sports Med 1996;24:594-602.

Dr. Stephen Lyman

Hospital for Special Surgery

Forster Center for Clinical Outcome Research

535 E. 70th Street, New York, NY 10021 (USA)

Tel. +1 212774 7125, Fax +1 212774 2455, E-Mail lymans@hss.edu 